\title{
Deimus y Phobus: la reposición moderna de la mi- tología y la oportunidad de destinarse
}

\author{
Deimus and Phobus: Modern Revival of Mythology \\ and Self-Destination Opportunity
}

\author{
ALBERTO I. VARGAS \\ Universidad de Navarra (España)
}

recibido:20.06.2015

aceptado:06.08.2015

\section{RESUMEN}

Este artículo aborda una comprensión de la crisis de la post-modernidad a partir de la mitología griega y la filosofía de la historia. Se propone la reposición del miedo interior como un fenómeno colectivo de la sociedad contemporánea que caracteriza nuestra situación cultural y que tuvo su aparición en el origen de la modernidad especialmente a partir del pensamiento de Hobbes, Lutero y Maquiavelo. Por último se propone como alternativa de superación de la situación crítica la apertura a la trascendencia desde la antropología como método.

PALABRAS CLAVE

MITOLOGÍA, MIEDO INTERIOR, ANTROPOLOGÍA, TRASCENDENCIA

Claridades. Revista de filosofía, 7 (2015), pp. 59-73

ISSN: 1889-6855 ISSN-e: 1989-3787 Dl.: PM 1131-2009

Asociación para la promoción de la Filosofía y la Cultura (FICUM) 


\title{
ABSTRACT
}

This paper explores an understanding of the Postmodern crisis through Greek mythology and philosophy of history. A revival of the interior fear as a colective phenomenon of contemporary society that characterize our cultural situation and that appeared with the modernity origin specially from Hobbes, Luther and Machiavelli influence. Finally, a overcoming alternative is proposed from an oppeness to God through Anthropology as a method.

\section{KEY WORDS \\ MYTHOLOGY, INTERIOR FEAR, ANTHROPOLOGY, TRASCENDENCE.}

\begin{abstract}
"Allí estaban los áureos caballos de rápidos pies del terrible Ares; y allí también el propio Ares, funesto portador de los despojos de los guerreros, con una lanza en sus manos, arengando a los soldados de infantería, enrojecido por la sangre, como si matara a seres vivientes, subido en un carro. Al lado estaban Terror y Miedo, ansiosos de meterse en la guerra de los hombres."1
\end{abstract}

¿QUÉ ES LO QUE ESTÁ MAL EN EL MUNDO? Hace ya más de un siglo que aquel agudo escritor británico puso de manifiesto el sentir generalizado de una sociedad sin esperanza ${ }^{2}$. ¿Presentía acaso Chesterton el terrible futuro de muerte que golpearía con las grandes guerras al mundo entero? Es que acaso, ¿tendría sospecha de la profunda herida que causarían los totalitarismos? ¿Se imaginaría siquiera la frustración social que el "peace and love" del 68 produciría algunas décadas después? ¿Sería capaz de comprender el vacío interior que el espíritu de lucro burgués había sembrado en el hombre? Seguramente no; sin embargo, es claro que algo estaba ya mal en el mundo.

Son muchos los intelectuales contemporáneos que entienden la situación actual de nuestra sociedad como crítica y decadente. Algunos como el historiador alemán, Oswald Spengler ${ }^{3}$, piensan que nuestra civilización está a punto de desaparecer como parte de un ciclo natural de decadencia en todas las culturas. Otros más optimistas, como el inglés Arnold J.

\footnotetext{
${ }^{1}$ Hesíodo, Escudo, 192-196.

${ }^{2}$ Cfr. Chesterton (1994)

${ }^{3}$ Cfr. Spengler, O. (2005).
}

Claridades. Revista de filosofía 7 (2015) 
Toynbee ${ }^{4}$ defienden que la moderna civilización occidental puede escapar a la norma general de decadencia de las civilizaciones pero no se aclaran en cómo conseguirlo. Joseph Ratzinger y Marcello Pera ${ }^{5}$ piensan con Toynbee que "la civilización está aprueba" y sólo será capaz de cambiar la tendencia y renacer si recupera su patrimonio común pues como dicen "el árbol tiene necesidad de raíces".

En 1983 Alexandr Solzhenitsyn -el nobel ruso- explicaba con sencillas pero poderosas palabras esta profunda situación de crisis: "Hace más de medio siglo, cuando aún era un niño, recuerdo haber oído a muchas personas mayores que daban la siguiente explicación a los grandes desastres que se habían abatido sobre Rusia: Los hombres se han olvidado de Dios, por eso ha sucedido todo esto" ". Tiempo antes ya había manifestado esta preocupación en la Universidad de Harvard insistiendo en la misma idea del mal en el mundo: "hay un desastre que ya está muy entre nosotros, la calamidad de una conciencia desespiritualizada y de un humanismo irreligioso",

Desafortunadamente la crisis de la post-modernidad después de mayo del 68 no se resolvió mediante una vuelta a los fundamentos para renovarlos, sino una huída hacia delante -propia del fugitivo- que desborda los límites de la propia cultura moderna. Años después se mantienen en nuestra sociedad síntomas de ese sentimiento masivo de miedo a partir de la desvinculación del hombre con la Trascendencia.

Ante el miedo producido por un mal, el hombre puede reaccionar de dos modos: superar el miedo enfrentándolo o huyendo de él. Inicialmente el miedo puede producir cierto parálisis, pero pronto el hombre se ve obligado a reaccionar. Pero ¿qué pasa cuando el hombre intenta huir de un mal que le sobrepasa y del cual es absurda la huída? Nadie puede soportar una situación así, es por eso que se gestiona en el hombre un modo distinto de huida en forma de olvido, de indiferencia, de evasión.

Esta reacción evasiva a partir del miedo tiene en nuestra sociedad occidental cinco claras manifestaciones que a su vez son el origen de un mayor malestar: el desamor, el escepticismo, el aburrimiento, la superstición y el suicidio, entre otros. ¿No es cierto que todos observamos una ruptura en el corazón humano y una sensación de fracaso en el proyecto

${ }^{4}$ Cfr. Toynbee, A. (1958).

${ }^{5}$ Cfr. Pera, M y Ratzinger, J. (2006).

${ }^{6}$ SOLZHENITSYN, A. (1983).

7 SOLZHENITSYN, A. (1978). 
más ambicioso que el hombre puede aspirar, amar y ser amado? ¿No es cierto que se huele en el ambiente una cínica incredulidad que -llena de indiferencia- huye del compromiso? ¿No es cierto que la mediocre frivolidad generalizada nos ha hecho insípidos y tediosos los manjares de la vida? ¿No es cierto que tocamos diariamente la decepción de la "diosa razón" y la búsqueda de respuestas en la emotividad que los nuevos ídolos brindan? ¿No es cierto que todos escuchamos cada vez más cerca los gritos de los que desesperados se quitan la vida o sobreviven en el sin sentido?

¿Qué es lo que habrá vivido Karol Wojtila en la Polonia nazi y comunista para que en su primer discurso como Papa haya planteado al mundo cruzar el umbral de la esperanza y vencer el miedo a Dios? Aun recordamos la imponente escena en el balcón de San Pedro que en 1978 asombró al mundo: "¡No tengáis miedo de acoger a Cristo y de aceptar su potestad! ¡Abrid, más todavía, abrid de par en par las puertas a Cristo!"

Pero, ¿es posible que junto a esa violenta e irracional propagación del mal se encuentre en lo hondo de nuestra sociedad un velado sentimiento de miedo? "El gran miedo es que el hombre -la humanidad- esté solo. Si no hay nadie más que nosotros, el encogimiento es la contrapartida de la inmensidad mundana. A su vez el encogimiento proyecta la violencia". Quizá sea esa la "enfermedad mortal" a la que Kierkegaard se refería hace años. Pero, ¿no es el miedo un sentimiento que padece el hombre en particular? ¿Puede entonces ser el miedo un fenómeno social, padecimiento colectivo? Y si así fuera, ¿qué es aquello a lo que nuestra sociedad le teme tanto y que le ha llevado a separarse de Dios?

$\mathrm{Al}$ parecer es una constante en todas las culturas el sentimiento religioso pues todas ellas de modos diversos resuelven el problema del origen del cosmos y del hombre a partir de la intervención divina. ¿Quiénes somos? y ¿a dónde vamos? han sido siempre la grandes preguntas que se plantea el intelecto humano, pero pronto aparecen otras -de ningún modo despreciables- donde inevitablemente el hombre se pregunta por el origen del bien y del mal. ¿Por qué son tan intensas y profundas las manifestaciones de este miedo? ¿Qué es lo que tiene este sentimiento que provoca la parálisis social, la indiferencia y la evasión?

\footnotetext{
${ }^{8}$ JUAN PABLO II (1978).

9 Polo, L. (1993), p. 58.
}

Claridades. Revista de filosofía 7 (2015) 


\section{LOS HIJOS DE LA GUERRA Y LA SENSUALIDAD}

Para los griegos el miedo estaba personificado en dos deidades míticas que el arte clásico ha representado siempre juntas y de un modo juvenil: Deimus y Phobus. El filósofo español Leonardo Polo señala que "el mito tiene un valor peculiar... no se debe ni se puede expulsar, pues constituye una modalidad sapiensal, que tiene aplicación práctica, ya que pensando o interpretando miticamente, se hacen accesibles aspectos verdaderamente reales del hombre" ${ }^{\prime 10}$.

Según cuenta el mito griego en labios de poetas como Hesíodo, Homero o Cicerón fue hace miles de años que el mundo comenzó y "lo primerísimo que nació fue Caos"11 pero enseguida Gea con su hijo Urano dio origen a los Titanes de entre los que se cuenta Crono. Así, Afrodita, la sensual diosa del amor, nació de la espuma del mar que produjo uno de los miembros inmortales que Crono corto a su padre y que la hermosa pintura de Botticelli ha dejado plasmada en el lienzo: "entonces fueron llevados a través del mar durante mucho tiempo; ambos lados, blanca espuma surgía del inmortal miembro y, en medio de ella nació una doncella"12, Afrodita.

La diosa del amor no fue la única hija de Crono pues antes Rea había concebido de él a Hestia, Deméter, Poseidón, Hera y Zeus. Sin embargo, en cuanto Gea y Urano revelaron a Crono que era su destino ser derrocado por alguno de sus propios hijos, Crono se los comió a todos excepto a Zeus que estaba por nacer. El día del parto Rea engañando a Crono, para proteger a su hijo, le mostró a cambio una piedra que al instante devoró pensando que sería Zeus, el último de sus hijos. Los años pasaron y Zeus fue criado en secreto. De acuerdo con la profecía, ya adulto derrocó a su padre y le forzó a vomitar a sus hermanos. Siendo ya rey de los dioses, Zeus tuvo cuatro hijos con su hermana Hera: Hefesto, Ilitia, Hebe y por último Ares, el famoso y terrible dios de la guerra.

A Ares era frecuente encontrarle en el campo de batalla y por su temperamento feroz y violento eran muy pocos los dioses del Olimpo que disfrutaban de su compañía. Afrodita era tan capaz como Ares de dejarse llevar por sus pasiones. El amor que Afrodita inspiraba era tan intenso, sensual y desenfrenado que nublaba todo tipo de razón, propio del enca-

\footnotetext{
10 Polo, L. (1993), p. 28.

${ }^{11}$ Hesíodo, Teogonía, 116.

12 Ibidem, 188.
} 
prichamiento y del deseo sexual. No es de extrañarse así que tuviera una gran influencia y control sobre numerosos dioses como Ares al que le convenció de apoyar a los troyanos en a aquella legendaria batalla ${ }^{13}$ de la Ilíada de Homero.

Se relata míticamente que Ares y Afrodita sufrieron la burla de Zeus, Poseidón y todos los dioses del Olimpo por la trampa que Hefesto les tendió ante el deshonroso deleite pasional que a ambos les gobernaba. Pero dejemos que sea Homero en palabras de Odiseo el que relate la historia:

\begin{abstract}
"En cierta ocasión se unieron amorosamente en la morada de Hefesto, en secreto. Ares le dio muchos regalos y deshonró el matrimonio y el lecho del soberano Hefesto. Pero pronto acudió a él como mensajero Helios, que los había visto acoplarse en el acto amoroso. Con que, en cuanto Hefesto hubo oído la amarga noticia, marchó hacia su fragua, cavilando venganza en su interior (...). Luego, tras haber construido su trampa (...) simuló que se iba hacia Lemnos (...). Ares echó a andar hacia la casa del ínclito Hefesto ansioso del amor de Afrodita de bella diadema. Pero por un lado y otro (de la cama) los envolvieron los lazos fabricados por el astuto Hefesto y no les era posible moverse en ningún sentido ni tampoco levantarse y se dieron cuenta de que ya no tenían fuga posible. Al verlos (Hefesto) gritó de manera terrible y llamaba a todos los dioses: «iZeus Padre y todos los otros dioses que existís para siempre, acudid a contemplar un suceso ridículo e indecente: cómo a mí, por ser cojo, Afrodita, la hija de Zeus, de continuo me deshonra y se entrega al pernicioso Ares, porque él es hermoso y de buenas piernas, mientras que yo quedé lisiado. ¡Pero pronto no querrán dormir juntos! Pues los retendrán a los dos la trampa y la atadura, hasta que su padre me devuelva mis regalos de boda, todo cuanto ofrecí por su hija, la cara de perra, porque es tan bella como desvergonzada»"14.
\end{abstract}

Como fruto de esta relación adultera contra Hefesto -hermano de Ares y esposo de Afrodita- estos dos singulares dioses tuvieron cinco hijos. Pero ¿cuál sería el resultado de una relación adultera entre la sensual afrodita y el violento Ares? ¿Qué temperamentos podrían surgir de la unión de tan grandes pasiones? Harmonia, Anteros, Eros, Deimus y Phobus fueron los hijos del amor y de la guerra.

En tres de los hijos brilló el atractivo de la sensual Afrodita. Harmonia, la diosa de la concordia, se le recuerda por el collar que recibió de Hefesto como regalo por su boda con Cadmo. Este collar traía la desgra-

\footnotetext{
${ }^{13}$ Cfr. Homero, Iiiada, V, 699.

${ }^{14}$ Homero, La Odisea, VIII, 265-320.
}

Claridades. Revista de filosofía 7 (2015) 
cia a todo aquel que lo poseía ${ }^{15}$. Harmonia y Cadmo terminaron convertidos en dragones y sus hijos llegaron a fin en medio de una tragedia. Eros, el hijo predilecto de Afrodita, era el dios del amor erótico, del amor sexual. Sin embargo, algunas tradiciones en la mitología lo consideraban el patrono del amor entre hombres, del amor homosexual. Se contaba que la reina Afrodita aviva el fuego que enloquece a los hombres por las mujeres, pero Eros convence la pasión de los hombres por los hombres ${ }^{16}$. Anteros era el dios vengador del amor no correspondido, de ahí su gran cercanía con su hermano Eros. Fue Anteros el que vengó a Timágoras por el suicidio que le provocó bajo traición la pasión por Meles el ateniense. Pero ¿qué se puede decir de Deimos y Phobos?

\section{DEIMUS Y PHOBUS: LAS 2 LUNAS DE MARTE}

Con el gran refractor de $66 \mathrm{~cm}$-muchos siglos después- en agosto de 1877, Asaph Hall descubrió en el Observatorio Naval de Washington los dos satélites del planeta Marte a los que llamó Deimus y Phobus. ¿Sabrían los griegos de la existencia de las dos lunas del planeta rojo, o serían los dioses del Olimpo los que los han dejado eternamente en el firmamento a la custodia de su padre?

Terror y Miedo fueron los gemelos que concibió por último Afrodita de su relación con Ares, el dios de la guerra. "Con Ares perforador de escudos, engendró Afrodita a los terribles Phobus y Deimus, que agitan las apretadas líneas de combate de hombres en la guerra que hiela de pavor con la ayuda de Ares, destructor de ciudades"17. En Deimus y Phobus, al parecer, lo que gobernó fue la violencia de su padre y la intensidad pasional de ambos progenitores. No es de extrañarse que a ambos se les recuerde siempre como los dos compañeros de Ares que a gritos demandaban la huida de todo guerrero anunciando a su paso la muerte, consecuencia de la guerra: "Como Ares, estrago para los mortales, va en busca de combate, y le acompaña el Miedo, su esforzado e intrépido hijo que pone en fuga al guerrero más contumaz" ${ }^{18}$. Pareciera así, que la concepción de la mitología griega con respecto a estas dos deidades estuviera íntimamente ligada con la biografía de su padre, la guerra.

\footnotetext{
${ }^{15}$ Cfr. Apolodoro, Biblioteca mitológica, III, 4.2.

${ }^{16}$ Cfr. Meleagro, Mousa Paidiké, 86. (Antología Palatina).

${ }^{17}$ Hesíodo, Teogonía, 934.

${ }^{18}$ Homero, Ilíada. XIII, 299.
}

Claridades. Revista de filosofía 7 (2015) 
Acompañando a Ares estaban siempre a su lado Deimus y Phobus. Estuvieron presentes en la vengativa batalla de Ares contra Heracles. Seguro que acompañaron a su padre en la guerra contra Sicyphus que atando a Thanatus (personificación mitológica de la muerte) pretendía que los hombres no muriesen más, pero Ares rescatándolo le restituyó su poder. Sin embargo, posiblemente su papel más destacado se dio lugar en la epopéyica Guerra de Troya narrada por el Homero donde Ares tuvo una participación relevante. Recordemos aquella discusión en el Olimpo donde los dioses intentaron convencer a Ares de no participar en la guerra ni vengar la muerte de su hijo Ascálofo: “Ares se golpeó los lozanos muslos con las palmas en las manos y dijo (a los dioses del Olimpo) estas lastimeras palabras: «No me vituperéis ahora los dueños de las olímpicas moradas, si voy a las naves de los aqueos a vengar la muerte de mi hijo, aunque mi destino sea caer fulminado por el rayo de Zeus y yacer junto a los cadáveres entre la sangre y el polvo». Así habló, al Terror y al Miedo mandó sus caballos uncir, y él se revistió con la resplandeciente panoplia"19.

Tan íntimamente unidos estaban Deimus y Phobus que en diversas ocasiones los poetas griegos los unían en un solo dios y con un solo nombre: miedo. El nombre de Deimus tiene un significado de huida, de fuga (así le llama la mitología romana) y generalmente se le nombra en castellano como Terror. Junto con otros terribles daimones, Deimus acompañó a Tisífone en su afán de volver loco a Atamas. Se recuerda también cómo su medio hermano Cicno, hijo de Ares y Pelopia, deseaba construirle un templo a Deimus con los cráneos de los hombres que mataba. En cambio de Phobus es el "Escudo" de Hesíodo el que nos da una descripción más detallada:

\footnotetext{
“Todo alrededor (del escudo) era brillante por el yeso, el blanco marfil, el ámbar y el resplandeciente oro. En medio, hecho de acero, estaba Phobus, que no se debe nombrar, mirando hacia atrás con sus ojos resplandecientes de fuego; su boca estaba llena de dientes blancos, terribles, espantosos, y sobre su horrorosa frente volaba temible incitando al combate, Eris, perniciosa, que quita el pensamiento y la mente de los héroes que le hacen la guerra al hijo de Zeus"20.
}

\footnotetext{
${ }^{19}$ Homero, Iliada, XV, 119.

${ }^{20}$ Hesíodo, Escudo, 142-150.
}

Claridades. Revista de filosofía 7 (2015) 


\section{EL MIEDO: EL GRAN FENÓMENO DE LA MODERNIDAD}

¿Será posible que los griegos profetizaran el terrible deseo de Deimus y Phobus de meterse algún día en la historia del mundo ${ }^{21}$ o sería simplemente un hermoso cuento mitológico? ¿No será más bien que los hombres de hace siglos comparten con los contemporáneos más de lo que nosotros imaginamos? ¿Será acaso que -en palabras de Don McLean- la música interior del hombre haya muerto, y que por el pecado entero de una sociedad que entiende al hombre en guerra y sometido a su sensualidad "Dios haya tomado el último tren rumbo a la costa" 22 y nos haya dejado sin su amparo? ¿Será tal vez que por su soberbia, el hombre se ha olvidado de Dios y ahora lleno de miedo ha perdido toda esperanza de salvación?

Posiblemente la pregunta más relevante sea: ¿cómo explicar que una sociedad haya logrado fundar sobre el sentimiento de miedo toda la civilización occidental contemporánea? En palabras de Jean Delumeau el miedo es una "enfermedad de nuestra civilización" que se padece a partir de la modernidad:

"La inversión de la coyuntura que se produjo en Europa en el siglo XIV es ahora bien conocida: la peste vuelve a aparecer... se inicia un repliegue agrícola, las condiciones climáticas se degradan y las malas cosechas se multiplican. Revueltas rurales y urbanas, guerras civiles y extranjeras devastan en los siglos XIV y $\mathrm{XV}$ a Occidente... la amenaza del peligro turco que acentuó su presión hasta Lepanto y del Gran Cisma, que a los hombres de iglesia les pareció el escándalo de los escándalos... y la gran ruptura de la Reforma Protestante. El estallido de la nebulosa cristiana incrementó desde entonces, al menos durante cierto tiempo, la agresividad intraeuropea, es decir, el miedo que los cristianos de occidente tuvieron unos de otros"23.

Tal vez sea necesaria, entonces, la comprensión de tres grandes ideólogos del pensamiento moderno que detonaron una revolución intelectual, política y religiosa en los primeros años de la modernidad y que influyeron en otros que después, tal vez con mayor talento, desarrollaron

${ }^{21}$ Hesíodo, Escudo, 192-196. "Al lado (de Ares) estaban Terror y Miedo, ansiosos de meterse en la guerra de los hombres."

22 Don MCLEAn (1971), The day the music died. Cfr. “.... and the three men I admire most: the Father, Son and te Holy Gost, they caught the last train for the coast the day the music died."

${ }^{23}$ Delumeau, J. (1989), p. 40. 
diversos sistemas de pensamiento con esta premisa: Hobbes, Lutero y Maquiavelo.

Siete años antes de su muerte en 1879 Thomas Hobbes escribió en su Autobiografía -Vita Thomae Hobbes Carmine Expressa- las memorias de su nacimiento: "estando de pronto en los mares del puerto las naves del enemigo español, (mi madre) con tal miedo concibió de forma prematura que nos parió a mí y al miedo juntamente" ${ }^{\text {24 }}$. ¿No es acaso profético que el hombre moderno y el miedo fueran como hermanos gemelos?

Al parecer esta pasión de la que tanto hemos hablado es el motor del contrato social hobbesiano. Para Hobbes es precisamente el miedo el origen del Estado y de todas las relaciones sociales y, sobretodo, es lo que lleva al hombre a abandonar su estado natural para rescatar la seguridad perdida que antes sólo la fe en Dios le había dado. No es de extrañar que este sea un tema recurrente en toda su filosofía social, ni tampoco que dedique en su obra máxima del Levitan un tratado sobre las pasiones y en especial del miedo. Si el "hombre es el lobo del hombre" entonces, ¿'en quién se puede confiar?, y si no se puede confiar en nadie, la guerra y el conflicto de todos contra todos son inevitables (bellum erga omnes) y por consecuencia el temor es constante. Pero ¿cómo es posible que este sentimiento se hubiese podido arraigar con tanta fuerza en Hobbes y en sus contemporáneos? Definitivamente su formación protestante fue una de las principales influencias en su pensamiento político y en general en su cosmovisión.

Polo señala que "Hobbes sigue siendo actual. Lógicamente, quien percibe en el hombre una voluntad agresiva sin freno, él no es el lobo mayor de todos -Hobbes no lo era- sólo puede temer. De ahí que lo específico del hombre sea la previsión de la amenaza. El aspecto hostil de la vida se extiende entonces hasta el miedo cósmico. El hombre se encuentra perdido en el mundo. Las estrellas, la inmensidad del universo con su inexplicabilidad mecánica, es decir, en su puro energetismo espontáneo, produce espanto. El único refugio es el Leviathan, dios suscitado por la entrega de nuestra propia sustancia dinámica"25.

Es conocido también el temor que atormentó a Martín Lutero, padre del protestantismo, ante la posibilidad de ser condenado. Podría afirmarse que todo su pensamiento está profundamente marcado por este te-

\footnotetext{
${ }^{24}$ Hobbes, T. (1966), p. 85.

25 POLO, L. (1993), p. 57-58.
}

Claridades. Revista de filosofía 7 (2015) 
mor. Lutero se sentía abandonado por Dios y su desesperación era una constante en su vida. No es de extrañarse que en sus 95 Tesis, clavadas el 31 de octubre de 1517 en la Iglesia del Palacio de Wittenberg, pusiera tanto énfasis en el miedo que el infierno producía los fieles cristianos.

Lutero le tiene tanto miedo al infierno que huye de Dios por temor a la condena pues, conocía muy bien las Escrituras: "A vosotros, amigos míos, os digo: no tengáis miedo a los que matan el cuerpo y después de esto no pueden hacer nada más. Os enseñaré a quién habéis de temer: temed al que después de dar muerte tiene poder para arrojar en el infierno. Sí, os digo, temed a éste"26. Como indica Polo, "Lutero no tiene proyecto religioso posible. Es la jubilación del cristianismo en términos antropológicos... El pesimismo antropológico por excelencia es la tesis según la cual el hombre no tiene nada que hacer respecto de Dios porque no puede amarle con toda su mente" 27 . Como es sabido, el pensamiento de Martín Lutero influyó en tal grado en los siguientes siglos que no es posible comprender la modernidad dejando a un lado el pensamiento protestante.

No es insensato pensar que de entre los contemporáneos de Lutero se encontrase la incipiente semilla del espíritu burgués utilitarista que tiempo después produciría un giro vertiginoso en la historia de occidente. Tampoco resulta increíble pensar que Hobbes se hubiera visto también influenciado directa o indirectamente por el "best seller" del siglo XVI: El Príncipe. Este tratado moral y político, publicado en 1532 y dedicado a Lorenzo II de Medici, fue el primero en muchos años en no citar a las Sagradas Escrituras ni a ningún autor de la antigüedad. En él Maquiavelo propone un fuerte y terrible cambio moral en el ejercicio del poder. Para él "es preferible ser temido que ser amado" para conservar el poder desde una perspectiva puramente pragmática pero también radicalmente egocéntrica que sobrepone el bien particular del común. Con Maquiavelo nace una nueva forma de gobernar $y$, por tanto, de organizar a la sociedad.

La historia posterior hasta nuestros días la conocemos todos, durante cinco siglos los hombres hemos pasado de la huída de Dios, al paulatino y aún insuficiente reconocimiento de que no somos "súper hombres".

${ }^{26}$ Lc. 12, 4-5.

27 PolO, L. (1993), p. 60.

Claridades. Revista de filosofía 7 (2015) 
Al parecer hay gran similitud entre los planteamientos griegos y los orígenes de la filosofía moderna. Ambos se encuentran en una situación de crisis social y de esplendor intelectual. "Aunque los filósofos del área de Atenas se encuentran sin duda en el marco de una cierta crisis, en el momento culminante del medievo hay temblores profundos, corrientes espirituales intensas a las cuales los pensadores responden y con las cuales, en parte, ellos mismos se templan y, en parte, también se destemplan cuando no son capaces de afrontarlas sin miedo",28.

\section{IV. ¡QUE SE VAYAN LOS DIOSES Y QUE VUELVA DiOS!}

Los gritos de los dioses Deimus y Phobus y la guerra que Ares ha hecho en el mundo, han provocado -como cuenta el mito griego- una "estampida" del hombre moderno ante Dios y lo Trascendente. "Pero -advierte Polo- no debemos quedarnos reducidos al mito, pues está hecho para ser superado, del mismo modo que en el hombre hay muchos aspectos que deben ser superados"29. Estamos hoy en un "parteaguas" de la historia y la dirección puede estar a punto de cambiar. Todo tiempo de cambio es tiempo de crisis y a toda crisis le corresponde un crecimiento, no sin antes pagar la cuenta natural del sufrimiento que provoca el esfuerzo de cambiar. Con palabras de Solzhenitsyn podemos decir que es tiempo de mirar hacia arriba:

"Si el mundo no se ha acercado a su fin, al menos ha arribado a una importante divisoria de aguas en la Historia, igual en importancia al paso de la Edad Media al Renacimiento. Demandará de nosotros un fuego espiritual. Tendremos que alzarnos a la altura de una nueva visión, un nuevo nivel de vida, dónde nuestra naturaleza física no será anatematizada como en la Edad Media, pero, más centralmente aún, nuestro ser espiritual no será pisoteado como en la Edad Moderna. La ascensión es similar a un escalamiento hacia la próxima etapa antropológica. Nadie, en todo el mundo, tiene más salida que hacia un solo lado: hacia arri$b a^{\prime \prime 30}$.

Nuestra sociedad contemporánea requiere y demanda de un nuevo ordenamiento, de una revolución -no política, ni científica- sino una revolución moral y antropológica. "Todos nosotros hemos sido testigos de cómo el progreso, en manos equivocadas, puede convertirse, y se ha

\footnotetext{
28 POLO, L. (1993), p. 43.

29 PolO, L. (1993), p. 28.

30 SOLZHENITSYN, A. (1983).
}

Claridades. Revista de filosofía 7 (2015) 
convertido de hecho, en un progreso terrible en el mal. Si el progreso técnico no se corresponde con un progreso en la formación ética del hombre, con el crecimiento del hombre interior, no es progreso sino una amenaza para el hombre y para el mundo" 31 .

Pero no una revolución moral que pretenda ser la medida de todas las generaciones, pues si así fuese cometería precisamente el mismo error que cometieron nuestros padres y además sería una gran mentira. Esta es una labor personal, pero también -y nunca excluida sino necesaria- una labor comunitaria. Como ha señalado recientemente Benedicto XVI:

"La búsqueda, siempre nueva y fatigosa, de rectos ordenamientos para las realidades humanas es una tarea de cada generación; nunca es una tarea que se pueda dar simplemente por concluida... Las buenas estructuras ayudan, pero por sí solas no bastan. El hombre nunca puede ser redimido sólo desde el exterior" 32 .

Si bien, en la modernidad se presenta una reposición del fatalismo mitológico, también se le presenta al hombre la oportunidad de abrir el futuro, destinarse trascendiendo. Aunque el pesimismo generalizado nos haga pensar de un modo recurrente que el futuro está obturado y que ya hay nada más que hacer, que se ha acabado para nosotros la posibilidad de crecer, es necesario recuperar el optimismo originario y profundo de nuestra condición. La oportunidad moderna consiste en esto, en abandonar el mito y abrirse a lo nuevo destinado el futuro:

"Lo más actual es el cristianismo. Basta recordar esa frase de la Epístola a los Hebreos: «Jesucristo es ayer, hoy y por los siglos». Y esta otra: «en él consta todo, en él está todo fundado», como dice San Pablo a los colosenses. Pues bien, esto no es mito, sino su más radical superación. Pero cuando se pierde esta comprensión reaparece el mito. ¿Por qué? Porque entonces el hombre se encuentra en pecado; y porque no sabe lo que es la Redención. Y desconfía. Por ello, tampoco entonces tiene claridad sobre el destino. El agnosticismo es la versión mítica del destino. Y es justificable, es verdad; pero bien entendido: porque un hombre que no está asistido actualmente por Dios, porque se ha apartado de Él, no puede destinarse a nada, y naufraga en el futuro" 33 .

\footnotetext{
31 BENEDICTO XVI (2009), n. 22.

32 Ibidem, n. 25.

33 Polo, L. (1993), p. 37.
} 
Parece que ha llegado el momento esperado: Deimus y Phobus deben llevarse a su padre al lugar de donde han venido y dejar en paz a los hombres. Ha llegado la hora de Dios.

Le dijo Atena, diosa virgen, diosa de la sabiduría:
“ $«$ A Ares!, reten tu poderosa fuerza y tus invencibles manos; pues no te es lícito quitarle la ilustre armadura, habiéndolo matado, a Heracles, el valeroso hijo de Zeus; pero ¡ea!, cesa en tu lucha y no me hagas frente. »
Así habló, pero no convenció al orgulloso ánimo de Ares, sino que él, dando un enorme grito, blandiendo sus armas semejantes a la llama, se lanzó rápidamente contra el fuerte Heracles, ansioso de matarlo, y le arrojó la broncínea lanza sobre el enorme escudo, irritado por la muerte de su hijo. Pero Atena desvió el impul- so de la lanza... un violento dolor se apoderó de Ares... y Diomedes lo hirió fuertemente en el muslo... y lo arrojó en medio de la tierra.
Le acercaron Deimus y Phobus el carro de bellas ruedas y los caballos, y después de levantarlo de la tierra, lo colocaron en el carro; y al punto fustigaron luego a los caballos para llevarlo al Olimpo...
Por su parte, Atena, de ojos verdes, se fue al elevado Olimpo, a las moradas de su padre Zeus"34

A partir de ese momento prohibió que los dioses intervengan en las guerras de los mortales.

El mito es sapiensal, pero la modalidad sapiensal más radical es la cristiana. Es tiempo de abrirse al futuro, sin olvidar que "estamos asistidos por el fundamento. A pesar de todo, a pesar de nuestros pecados, Dios no nos ha dejado de su mano. Las cosas y nosotros estamos en las manos de Dios ahora, y por tanto, los proyectos que emprendemos los podemos destinar. Somos capaces de un destino. No estamos sometidos a un destino fatal, sino que somos capaces de ejercer nuestra destinación en sentido creativo" 35 .

\section{Bibliografía.}

APOLODORO. Biblioteca mitológica.

BENEDICTO XVI (2009), Caritas in veritate.

CHESTERTON, G. K. (1994), What's wrong with the World, Ignatius, San Francisco.

DELUMEAU, Jean (1980), El miedo en Occidente, Taurus, Madrid. HESÍODO. Escudo.

\footnotetext{
34 Hesíodo, Escudo. 446-471.

35 PolO, L. (1993), p. 38.
} 
HESÍODO. Teogonía.

HOBBES, Thomas (1966), Vita Thomae Hobbes Carmine Expressa, Opera Latina de Gulielmi Molesworth, Alemania, 1966.

HOMERO. Iíada.

HOMERO, La Odisea.

JUAN PABLO II, Homilía del 22 de octubre de 1978.

MELEAGRO, Mousa Paidiké, (Antología Palatina).

PERA, Marcello y RATZINGER, Joseph (2006), Sin raices. Europa, relativismo, cristianismo, Islam, Península, Barcelona.

POLO, Leonardo (1993), Presente y futuro del hombre, EUNSA, Pamplona.

SOLZHENITSYN, Alexandr (1983), Men have forgotten God, The Templeton Address, USA.

SOLZHENITSYN, Alexandr (1978), A world split apart, The Harvard Address, Cambridge, MA.

SPENGLER, Oswald (2005), La decadencia de occidente, RBA, Barcelona.

TOYNBEE, Arnold (1958), La civilización puesta a prueba, Emecé, Buenos Aires.

Alberto I. Vargas es licenciado en Ciencia Política (Tecnológico de Monterrey, México) y doctor en Filosofía (Universidad de Navarra). Actualmente es vicepresidente del Leonardo Polo Institute of Philosophy (South Bend, IN, USA) e investigador del Instituto Empresa y Humanismo de la Universidad de Navarra. También es profesor visitante en Strathmore University (Kenya), Leidenhoven College (Holanda), Universidad Santo Toribo de Ogroviejo (Perú), Universidad de los Hemisferios (Ecuador), Universidad Panamericana (México).

Linea de Investigación:

Antropología filosófica, filosofía política y teoría del conocimiento

\section{Publicaciones recientes:}

- "Abandonar-se: el problema puro y la oportunidad moderna", en ZORROZA, I. El hombre como solucionador de problemas, Cuadernos de Pensamiento Español, Universidad de Navarra, Pamplona, 2015.

- "La crisis antropológica de la innovación científica", Scientia et Fides, Torun, II/1 (2014), 9-30.

- "El carácter de sólo: una teoría antropológica de la desesperación”, en GARCÍA, J.A, Escritos en memoria de Leonardo Polo. Persona y acción, vol. II, Cuadernos de Pensamiento Español, n. 54, Universidad de Navarra, Pamplona, 2014, 161-199.

Dirección electrónica: avargas@leonardopoloinstitute.org

Claridades. Revista de filosofía 7 (2015) 